\title{
O sistema de acompanhamento em compras e logística numa organização pública*
}

\section{The follow-up system in the purchase procedure and logistics in a public organization}

\author{
Mauricio Kalau Gonzales**
}

\begin{abstract}
Resumo
O artigo analisa a aplicabilidade do sistema de acompanhamento em compras e da logística numa organização pública. O local estudado foi o restaurante universitário (R.U.) na Universidade Estadual de Londrina. Após terem sido colhidas as informações e os dados pertinentes, apresentados para o foco do problema e analisados os resultados obtidos, verificou-se que o sistema de acompanhamento em compras é utilizado informalmente no órgão especificado, apesar de sua importância, embora na universidade, não se adote o mesmo sistema para os órgãos que a integram. Na comparação feita entre uma empresa pública e a caracterização do sistema em uma empresa privada, verificou-se que o sistema utilizado na empresa privada é mais completo, como um procedimento rotineiro de serviço do departamento de compras, do que o adotado pelo órgão público. Com relação ao sistema de logística que integra o sistema de compras, verificou-se que existem falhas na sua forma de concepção e de aplicação gerando, desvios e perdas de recursos utilizados no setor público. Foram apontadas formas para se tentar resolver os problemas levantados, entre elas a possibilidade de adoção do sistema de concessão pública, da forma como é adotado em outros serviços públicos na cidade de Londrina.

Palavras-chave: Aplicabilidade, acompanhamento, compras, sistema, empresa, pública, privada.
\end{abstract}

\begin{abstract}
The Article discuss the applicability of the follow-up system in purchase and logistics in a public organization. The study took place at the restaurant (R.U.) of the State University of Londrina (UEL). After gathering information and relevant data and analyzing the results obtained, it was possible to verify that the follow-up system in the purchase procedure is informally used in that location, despite its importance. It could also be noticed that the university does not use the same system with the other units that integrate it. When comparing a public and a private company it is possible to conclude that the system used in a private company is more complete, as it is considered a routine procedure of the purchase department. As for the logistics system which integrates the purchase system, it was possible to verify that there are flaws in its conception and use, generating deviation and loss of resources used in the public sector. Some possible ways to solve the raised problems were pointed out, such as: the possibility of adopting the system of public concession in the same way that it is adopted in other public services in the city of Londrina.
\end{abstract}

\section{Introdução}

Key words: Applicability, follow-up, purchase, system, organization, public, private.

\footnotetext{
* Esta monografia pertence ao acervo da STN - Secretaria do Tesouro Nacional.A íntegra desta pesquisa está à disposição no Departamento de Administração da UEL.

** Professor do Departamento de Administração da UEL. Especialista em Metodologia do Ensino Superior - UEL. E-mail: mauriciokg@uel.br. Fone: (43)3348-5164
} 
O propósito deste trabalho é um estudo da aplicabilidade do sistema de acompanhamento em compras utilizados na iniciativa pública e iniciativa privada de uma maneira comparativa. É comum estudar-se aspectos do uso de um sistema gerencial específico em empresas de iniciativa pública ou privada, porém comparar um mesmo sistema de gerenciamento em empresas com características e funções claramente diferentes entre si no mundo capitalista não é comum.

A comparação entre o sistema de acompanhamento em compras nos dois setores especificados traria objetivamente contribuições à sociedade como um todo, mas estudou-se também os aspectos de logística relacionados. Considerando que o termo logística é amplamente utilizado quando se tenta explicar as interações sistêmicas em uma empresa, surge o termo logística aplicada que, por definição, engloba os sistemas de finanças, produção, marketing, recursos humanos, informática e outros e seus vários sub-sistemas na empresa.

Nesta pesquisa os dois assuntos, tomados como tema, foram tratados dentro de uma visão objetiva de complementariedade e de dependência, ou seja, a aplicabilidade do sistema de acompanhamento em compras e de logística numa organização pública.

A pesquisa foi realizada num restaurante, onde a especificidade do trabalho de aquisição de mercadorias demanda uma agilidade enorme dos seus administradores para que o material adquirido, a maioria perecíveis a curtíssimo prazo, não se perca, e não falte e nem reste demasiadamente, justamente para não acarretar mais prejuízos de recursos ao longo de sua manipulação. Outro fator, interessante, motivou a realização deste trabalho: a característica pública, geralmente, de morosidade administrativa, em contraposição com a necessidade de se fazer praticamente todos os dias da semana do período letivo uma, quantidade substancial de refeições para a comunidade universitária.

Em função da quantidade e qualidade das informações e do uso cada vez mais freqüente dos sistemas eletrônicos de acesso a bancos de dados, como a internet, mostrou-se também no presente trabalho, o uso deste sistema relacionado ao tema proposto.

\section{Justificativa}

Ao se administrar uma empresa, o administrador tem à sua frente as mais diversas tarefas diretamente relacionadas ou não à obtenção de resultados. Dentro da complexidade das funções exercidas no atributo do seu trabalho, muitas vezes, este gestor utiliza-se das habilidades requeridas ao correto desempenho da função, habilidades estas que são específicas ao atendimento das necessidades exigidas para o cumprimento do trabalho. Tais habilidades podem ser inatas ou adquiridas, através de estudos sobre o assunto, interações com o meio ambiente e desenvolvem-se com o passar do tempo. Dependendo, de indivíduo para indivíduo, cada um desenvolve mais ou menos estas habilidades, sendo os mais capazes ao desempenho da função aqueles que desenvolveram mais e têm a oportunidade de utilizar as habilidades adquiridas.

Porém no estudo em questão existe uma particularidade que diz respeito à aplicabilidade de um sistema, comparativamente ao seu uso, numa empresa de cunho público com outra de cunho privado. Notadamente, estas empresas, quanto à essência de sua função e objetivos, são diferentes.

Então é necessário, para que o leitor tenha uma visão daquilo que se propõe, fazer uso de uma analogia. Focalizaremos a empresa como se fosse uma orquestra, que é composta por vários instrumentos, tendo cada instrumento músicos capazes de tocá-los. Sabe-se que, numa orquestra, existe um regente ou maestro. Por que existe uma orquestra? Poderíamos responder de várias formas, mas primordialmente a função de uma orquestra é tocar uma obra musical, conservando assim, sua aplicação e imutabilidade no tempo. Pois bem, para gerir uma empresa também é necessário que ela tenha os instrumentos de gestão mínimos à realização do bom andamento do trabalho e pessoas treinadas 
para corretamente fazerem uso de tais instrumentos. O apreciador de uma música notará claramente a falta ou a incorreta utilização de um instrumento na apresentação de obra clássica. Esta falta pode comprometer, dependendo da obra que se propõe a apresentar, todo o conjunto. Então por que se estudar o sistema de acompanhamento em compras? Justamente porque ele é um dos instrumentos de gestão que colaboram, como apoio, para o resultado da empresa. Sem ele, as compras realizadas pela empresa não teriam parâmetros eficazes de gerenciamento, tal como um instrumento na orquestra, fundamental para a realização da obra. Mas existe um outro detalhe relevante que diz respeito à essência dos tipos de empresas estudados, a saber, a empresa pública e a privada.

Enquanto na empresa privada sempre existe um dono ou sócios que se solidarizam, no objetivo comum de administrar seu negócio, o mesmo não acontece na empresa pública. Esta, é geralmente administrada por políticos eleitos, por direito, direta ou indiretamente, mas apenas para exercerem um mandato, no decorrer do tempo pré-estabelecido para a função pública, o que geralmente não acontece na empresa privada, pois os donos ou sócios são os que a conduzem, quase sempre por um longo período de tempo, dando seqüência assim ao desenrolar de técnicas e de instrumentos, que os auxiliam na condução e na melhoria gerencial, sendo eles mesmos responsáveis pelo sucesso ou não de seu empreendimento. Voltando ao uso da analogia sugerida, qual seria o resultado, no caso da empresa pública, ao ver o dirigente (maestro) sendo substituído por outro ao término de uma música, durante a apresentação de um concerto e, o outro maestro começando seu mandato (apresentação do concerto) de uma forma totalmente diferente de seu antecessor, mudando o rumo de políticas adotadas e deixando outras políticas (ou músicas) que seriam necessárias para se finalizar o concerto da forma como se havia proposto? Pior ainda quando a substituição é feita durante o mandato ou, analogicamente, substituindo um maestro por outro durante a apresentação de uma música. $\mathrm{O}$ uso desta analogia esclarece a quem administra, o nível de administração em que se encontram muitas das empresas que, no decorrer deste trabalho, serão citadas por aquilo que fizeram ou estão fazendo na arte de administrar e não raramente, empresas do setor privado. São poucos os exemplos de empresas ou de serviços públicos, que se empenham na utilização do instrumento sistema de acompanhamento em compras, que se possam comparar, em nível de eficiência ou de resultados, ao de empresas privadas.

Tais empresas privadas, que aplicaram com afinco no desenvolvimento dos seus trabalhos, durante o transcorrer do tempo, técnicas de gerenciamento como, melhoria contínua, princípio da pequena diferença, zero defeito, entre outras, além de poderem estar atuando com competitividade frente à sua concorrência, conseguiram também extrapolar alguns aspectos no gerenciamento específico do sistema de acompanhamento em compras, quando trouxeram para dentro de suas instalações fabris, o próprio fornecedor, fazendo com que toda a logística de gerenciamento se adaptasse ao novo conceito de produção implementado. Logicamente este é um exemplo que se desenvolveu a partir dos conceitos de terceirização e que foram se aprimorando.

Medidas empresarias que minimizam o desperdício de recursos sempre deveriam ser o objetivo da empresa, ao procurar caminhos de progresso no seu negócio. Essas ações, corretamente dirigidas, seriam uma das formas pelas quais a empresa alcançaria desenvolvimento, tendo como conseqüência poder para atuar cada vez melhor no mercado.

\section{Metodologia}

De acordo com Contandriopoulos et al. (1994) esta é uma pesquisa de desenvolvimento, apresentado-se como a estratégia que visa, utilizando de maneira sistemática os conhecimentos existentes, elaborar uma nova intervenção ou melhorar consideravelmente uma intervenção existente. 
Utilizou-se o método comparativo, descrito por Lakatos e Marconi (1991, p. 82): “Ocupando-se da explicação de fenômenos, o método comparativo permite analisar o dado concreto, deduzindo do mesmo os elementos constantes, abstratos e gerais", seguindo o método indutivo, comparativo, utilizou-se em conjunto com a observação direta intensiva, com técnicas de entrevista não estruturada.

A população pesquisada nos órgãos especificados neste trabalho foram as pessoas diretamente envolvidas nos procedimentos de compras e recebimento de materiais, que fazem parte das rotinas de trabalho do sistema especificado.

As entrevistas e a coleta de dados foram realizadas pelo pesquisador e por alunos selecionados.

Os objetivos específicos delimitados na pesquisa foram os seguintes:

a) analisar os fluxos de informações geradas nos processos de compras e seu acompanhamento;

b) analisar as técnicas de acompanhamento de compras utilizadas. (formulários e rotinas existentes);

c) analisar os resultados obtidos na gestão de compras e acompanhamento no restaurante universitário;

d) caracterizar um sistema de acompanhamento em compras e logística.

Os procedimentos especificados para serem utilizados nesta pesquisa com o intuito de se atender aos objetivos propostos e realizados foram os descritos a seguir.

1) Comparou-se o sistema de acompanhamento em compras e logística, caracterizado com o sistema em funcionamento no órgão especificado, identificando suas peculiaridades no uso público.

2) Dentro de análise de fluxo de informações, foi feita uma análise de todos os tipos de fichas e cadastros de fornecedores, e os dados nelas existentes, juntamente com o procedimento envolvido.
3) Verificou-se todos os controles de estoques e seu modo de utilização.

4) Descreveu-se todos os problemas inerentes ao acompanhamento das compras no restaurante universitário (R.U.) e Diretoria de Materiais (em relação às compras) assim como se apontaram possíveis soluções.

\section{Conceitos}

\section{Sistema}

[...] é um conjunto de partes coordenadas para realizar um conjunto de finalidades. Um animal, por exemplo, é um sistema com muitas partes (subsistemas) que atuam de forma coordenada e integrada para atender a várias finalidades: autoconservação, reprodução, criação de prole, etc. (CHURCHMAN apud ALVARENGA; NOVAES, 1994, p. 48; grifo do autor).

\section{Acompanhamento em Compras (Follow-up)}

Acompanhamento em compras é um sistema gerencial usado no setor de aquisição de matériasprimas das empresas. Este sistema possibilita às pessoas envolvidas no processo de compras tomar decisões que culminem com a entrega das mercadorias (logística) de acordo com o que foi pedido, ou seja, nos prazos corretos, nas quantidades corretas e de conformidade com a especificação dos produtos solicitados e ainda um caminho de negociação com fornecedores. Também possibilita à empresa, condições de análise que minimizam a perda ou desvio de recursos.

\section{Logística}

As questões de entrega de mercadorias estão relacionadas ao procedimento de acompanhamento das compras efetuadas até a sua recepção pelo órgão solicitador. Para isto acontecer, a seqüência do sistema (burocrático) de aquisição da mesma deve estar sincronizada com a seqüência de recebimento. 
Isto quer dizer que, tanto a responsabilidade de entrega da mercadoria pelo fornecedor e como recepção desta pelo comprador, são trabalhadas no sistema de logística e de acompanhamento em compras. Um grande fundamento que integra estes dois conceitos nos é dado por Oishi (1995, p. 28): "Movimentação está para produzir. Produzir é dar um passo no processo de transformação. É necessário estar atento à eliminação da movimentação não ligada à produção." De uma forma simples, então, a definição de logística para este estudo será: "Administração do sistema que integra o pedido, a recepção e a conferência de materiais."

Convém mencionar ainda, os comentários de Alvarenga:

Deve ser lembrado que a logística é um campo muito vasto, que incorpora de maneira integrada diversas áreas técnicas. Assim, é mais sensato ir se aprofundando aos poucos, em níveis sucessivos de conhecimento, adequando o aprendizado às necessidades da vida profissional. (ALVARENGA; NOVAES, 1994, p. xxi).

\section{Objeto}

O sistema de acompanhamento em compras pode ser aplicado numa organização pública? As características de tal aplicação seriam as mesmas adotadas numa organização privada? Quais são as conseqüências da não aplicação de tal sistema em uma empresa?

Estas perguntas estão sendo colocadas em ordem de prioridade para resposta, por serem de vital importância para o entendimento do assunto ora estudado.

$\mathrm{Na}$ iniciativa privada, o administrador se esmera para não deixar faltar mercadorias a seus clientes e, muitas vezes, ainda oferece uma gama de opções de produtos como forma de atrativo, sem, é claro, investir demasiadamente em estoques, tendo assim que gerenciar as compras de uma forma muito atuante. Mas numa organização pública, muitas vezes, o encarregado do setor de compras e licitações não raramente desconhece o sistema de acompanhamento em compras como instrumento de gerenciamento isto em função dos objetivos distintos das duas organizações, como expõe Reis:

Na administração pública fator preponderante, que a destaca da administração privada, é que a entidade pública não pode dispor livremente, como as entidades privadas, dos valores que integram o seu Patrimônio. Eis, pois, a grande diferença entre o Patrimônio privado e o governamental, sempre em função dos objetivos que ambas perseguem. $\mathrm{Na}$ administração privada, principalmente na de empresas, o objetivo principal é o lucro, que remunera o capital empregado; na administração pública a entidade busca o lucro, que se apresenta sob a forma de "satisfação social" proporcionada à coletividade (REIS, 1979, p. 131).

A preocupação do comprador público resumese, na maioria das ocasiões, a saber se a mercadoria chegou ao solicitante. Até mesmo aspectos de conferência do objeto comprado são geralmente relegados. Então, ao se perguntar se o sistema de acompanhamento em compras pode ser aplicado numa organização pública, deve-se responder na forma de quantos benefícios se conseguiriam com a sua correta utilização, além de ser um dever utilizálo corretamente. O benefício seria a clareza, perante o público que paga impostos, de ter a certeza da correta utilização do material ou de produto comprado para uso no setor público com o mínimo desperdício, mostrando-se assim zelo pelo bem comum.

$\mathrm{O}$ enfoque dado ao sistema de administração pública no Brasil, na atualidade, gera muitas brechas para que haja desvios e impedimentos ao bom andamento das compras efetuadas:

O artigo 49 da lei no. 8.666 prevê a possibilidade de revogação da licitação por interesse público decorrente de fato superveniente devidamente comprovado, pertinente e suficiente para justificar tal conduta, bem como a obrigatoriedade de sua anulação por ilegalidade, neste último caso podendo agir de ofício ou por provocação de terceiros, mediante parecer escrito e devidamente fundamentado. (DI PIETRO, 1996, p. 293; grifo nosso). 
Numa organização privada muitos desvios podem acontecer mas, certamente a correção pelo seu dirigente será feita de forma mais rápida ou, então, a empresa não suportará, por muito tempo, a situação de descontrole nos gastos e não suprimentos e seu objetivo de obter lucro estará, assim, comprometido:

Diferente da Administração privada, em que o controle é exercido e imposto pelo empresário, no âmbito da Administração Pública a função controle é exercida por circunstâncias da Administração, em decorrência de imposições governamentais. (REIS, 1979, p. 15).

Com a ajuda do sistema de acompanhamento em compras, todo o processo de compras após terem sido negociados com fornecedores ou parceiros empresariais, podem sofrer verificação. Sobre a necessidade de se manter um sistema de acompanhamento nas compras, citamos Gurgel:

Considerando a inversão da posição comercial, que se manifesta após a entrega do pedido ao fornecedor, torna-se necessário criar um instrumento de pressão para aumentar as garantias da empresa quanto aos cumprimentos dos prazos de entrega por seus fornecedores. (GURGEL, 1996, p. 50).

O mais importante, porém, é ter um caminho de forte ligação com tais fornecedores para durante o procedimento de entrega das mercadorias poder se negociar eventuais vantagens ou ajustes. Isto se dá não somente em empresas situadas em grandes centros, mas também nas do interior. Por exemplo, caso haja repentinamente uma maior demanda pelo produto, o empreendedor privado pode pedir o acréscimo consentido pelo fornecedor, de mais mercadorias para um mesmo pedido, antes da entrega das matérias-primas requeridas. Tais vantagens e ajustes são elencadas por Dias:

Acompanhar, documentar e fiscalizar as encomendas realizadas em observância aos respectivos prazos de entrega; informar ao comprador o resultado do acompanhamento; efetuar cancelamentos, modificações e pequenas compras conforme determinação da chefia. (DIAS, 1983, p. 294).
No gerenciamento público, efetuar cancelamentos, modificações e pequenas compras, é, via de regra, proibido, se não houver amparo legal, dependendo dos valores a que se referem as compras e também pela falta de vínculo mais profundo e transparente com os fornecedores. O sistema de acompanhamento em compras, quando aplicado no setor público, passa antes pelo atendimento e pelo crivo das especificações das leis e princípios de compras públicas. Apesar das dificuldades no gerenciamento, com o passar do tempo, um bom sistema implantado gera comodidade aos usuários. Agora como seria se não existisse tal sistema?

Uma das respostas seria a impossibilidade de se implantar outros sistemas como, por exemplo, o Justin-Time (No tempo certo), dada a necessidade, nesse sistema, de se ter, a cada momento, a certeza do fornecedor na entrega da mercadoria pedida; ou tomar decisões de substituição urgente de fornecimento, em virtude de se ter detectado, através do sistema de acompanhamento em compras, a impossibilidade, por qualquer motivo, da entrega de mercadoria pelo fornecedor contratado em primeiro plano. Além disso, a base frequiente de ligação entre fornecedor e empresa não está somente no momento das negociações das compras e sua efetivação. $\mathrm{O}$ amadurecimento de tais relações entre empresas e fornecedores faz-se ininterruptamente na empresa privada. Chega-se, muitas vezes, a se ter tal grau de cumplicidade nestas relações que os nomes dos compradores passam a fazer parte do produto fornecido pelo fabricante, dependendo do poder de barganha dos compradores, de suas necessidades e das políticas de compras e de marketing das empresas compradoras e fornecedoras. Freqüentemente, em empresas com alto poder financeiro e com estratégias de marketing próprias, isto acontece. Existe ainda, atualmente, a possibilidade do uso deste sistema com o foco na rastreabilidade de produtos. Exemplos desta aplicação no Brasil, recentemente, são constatados e noticiados amplamente pela mídia impressa e televisiva, na área de peças de automóveis, com os já tão conhecidos e normalmente indesejados recalls. 
Também, em razão de políticas de controle de qualidade e sistemas como as normas de gestão ISO 9000 e ISO 14000, que colaboram e podem complementar o gerenciamento do sistema de acompanhamento em compras. Porém, como se dá esta cumplicidade em empresas do setor público? Ela é esporádica não gerando, ao longo do tempo, aprimoramento ou amadurecimento nas relações de fornecimento, na maioria das vezes. O Quadro 1 ilustra características de parcerias no setor público e setor privado. Isto, para se atender às regras, geradas na lei de licitações $\mathrm{n}^{\circ}$ 8.666/93, e os princípios orçamentários e sua validade, conforme descrito por Giacomoni:

Esse dispositivo constitucional é regulado pela Lei no. 8.666, de 21-6-1993, que estabelece as normas gerais sobre licitações e contratos administrativos relativos a obras, serviços, inclusive de publicidade, compras, alienações, concessões, permissões e locações, no âmbito da administração direta, autarquias, fundações públicas, empresas públicas, sociedades de economia mista e demais entidades controladas direta ou indiretamente pela União, Estados, Distrito Federal e Municípios. (GIACOMONI, 1998, p. 231).

Mesmo que, geralmente, não apareça a oportunidade de se fazer esta aplicação nos sistemas

Quadro 1 - Parcerias envolvidas.

\begin{tabular}{|c|c|c|}
\hline \multicolumn{2}{|c|}{ PARCERIAS DESENVOLVIDAS } \\
\hline Setor & Público & Privado \\
\hline Característica & Licitações Públicas & Direção da Empresa \\
\hline Decisão & Esporádicas & Duradouras \\
\hline Tempo & Casual & $\begin{array}{c}\text { Rotineira e efetiva } \\
\text { Associações empresariais } \\
\text { (nome) }\end{array}$ \\
\hline Reciprocidade & & \\
\hline
\end{tabular}

de acompanhamento em compras nas empresas públicas, em muitos casos, há a necessidade de usálos. O caso do restaurante universitário da Universidade Estadual de Londrina é um deles. Seu administrador faz o trabalho de acompanhamento em compras de alguns produtos, empiricamente; mesmo não sabendo, o que está fazendo é exatamente o uso do sistema de acompanhamento em compras, na sua forma de fazer acontecer um procedimento de produção das refeições. São esforços de pessoas que têm o compromisso de atendimento a um trabalho proposto e não de um sistema implantado, para que, de modo sistemático, possam colher resultados. Isto, no sistema público, é mais um problema de ordem, a saber, a colocação de pessoas apontadas para o cargo e não um sistema capaz de absorver e treinar adequadamente pessoas, independentemente de suas boas relações com os dirigentes públicos. Pereira e Spink (2001, p. 40 ) exemplificam: "Muitos problemas que surgem quando se criam instituições do Estado devem-se ao fato de os políticos eleitos e burocratas nomeados terem interesses e objetivos próprios." Na empresa privada é comum acontecer o contrário, ou seja, existência de um sistema que absorve pessoas capacitadas sim, mas que são treinadas a utilizar a sistemática adotada pela empresa para cumprimento de seus objetivos, e que seguem e contribuem com os objetivos patronais.

\section{Revisão de bibliografia}

\section{Contextualização}

Atualmente, a necessidade do sistema de acompanhamento em compras num órgão público é de importância, não somente para se evitar perdas na continuidade de trabalhos que dependam de sua colocação para aqueles que fizeram sua solicitação, como também para comprovações burocráticas e legais do serviço de aquisição realizado por tal órgão:

A universidade moderna tem que ser colocada no centro dos graves problemas da nação, para melhor contribuir para a solução dos mesmos. Ela não pode ser um castelo de marfim, reduto escondido, sob o falso pretexto de que as atividades aplicadas maculam a pureza da ciência. Ela deve ter uma postura gerencial,cabendo-lhe a responsabilidade de identificar os problemas de educação, de saúde e produção,conscientizando a comunidade da existência e da importância desses problemas e procurando resolvê-los através da cooperação ativa dessa mesma comunidade. (VASCONCELOS FILHO, 1985, p. 42). 
Além disso, há que se considerar que o volume financeiro, envolvido nas compras de alguns órgãos públicos, superam o orçamento de pequenos municípios brasileiros, como é o caso da Universidade Estadual de Londrina, necessitando assim de um gerenciamento eficaz que minimize perdas financeiras na sua execução. O sistema de acompanhamento em compras existente, mesmo que informalmente, na Universidade Estadual de Londrina merece ser corretamente utilizado e otimizado, uma vez que os benefícios advindos de seu uso correto facilitam a rotina de trabalho das pessoas que o utilizam e da comunidade:

Não basta arrumar, simplesmente, os documentos; mas anotar, em síntese, os elementos e informações que contém, classificando-os segundo uma norma, a fim de que, em qualquer época, se tenha em resumo, o conteúdo de cada documento. Surgem, então, as fichas remissivas que devem receber as anotações sucintas referentes aos documentos, sendo necessário mantê-las organizadas em processo de fácil memorização, flexibilidade de pesquisa e acessibilidade de procura. (MIRANDA, 1968, p. 209).

A consistência das informações impressas ou arquivadas eletronicamente deve, a partir de sua coleta e através da forma como estão sendo apresentadas, gerar confiabilidade para aqueles que estarão envolvidos em futuros processos de pesquisa de dados. Se isso não ocorrer, o exemplo de transparência na gestão de um empreendimento, principalmente daquilo que é público, em sua essência, estará prejudicado. Oliveira (1995, p. 33) diz: “A empresa deve estabelecer e manter procedimentos documentados que assegurem que os produtos comprados estejam de acordo com os requisitos especificados." E acrescenta Oliveira (1995, p. 34) que a empresa deve: "[...] criar um programa de avaliação de fornecedores"; considerando que:

Os fornecedores avaliados devem ser acompanhados em seus fornecimentos. Para isto, uma das formas é estabelecer um sistema de méritos e deméritos, em função da qualidade de suas entregas. Estas informações devem ser registradas (em fichas de fornecedor, ou num banco de dados informatizado) para poder alterar o status de fornecedor.
Exemplo: - fornecedor com muitos deméritos podem ser desqualificados; - fornecedor sem problemas num curto período de tempo pode tornarse qualidade assegurada, dispensando-se a inspeção. (OLIVEIRA, 1995, p. 35; grifo nosso).

Reis (1979, p. 9) diz haver, na transcrição de dados, um objetivo contábil para: “[...] orientar o Prefeito e as demais autoridades municipais na observância das leis e dos princípios de exação e legalidade dos gastos públicos, adequando, por conseguinte, a Administração municipal para o seu cumprimento."

Sobre princípios orçamentários afirma Giacomoni (1998, p. 65): "Estes princípios podem ser úteis como meio de se estudar alguns aspectos do processo orçamentário. Se considerarmos, todavia, como mandamentos, são completamente irreais. Os governos com excelentes sistemas orçamentários violam essas regras com bastante frequiência."

Teixeira (1999, p. 99) confirma: "A falta de integração entre os diversos orçamentos foi constatada em todas as fases do processo orçamentário, ou seja, na fase de elaboração, de acompanhamento da execução e da avaliação dos resultados."

Nas compras públicas, os problemas específicos relacionados com o orçamento público têm solução?

Aponta Teixeira (1999, p. 102) que: "Desse sistema nasceu na administração pública brasileira, o que se chama de química, isto é, a transposição ilegal de recursos de uma para outra rubrica."

Eliyahu M. Goldratt, em seu livro A Meta, nos faz refletir sobre os pontos de estrangulamento na produção (gargalos) ou teoria das restrições, e ensina a eliminá-los. O questionamento que se faz é: Se existe um problema na empresa e procura-se uma forma de resolvê-lo, qual o fator que impede a implantação da solução? Quando conhecemos um problema e sabemos a possível resposta e não a implementamos, ainda que possível, é o mesmo que afirmar que o problema não é problema. 


\section{Conforme Heinritz:}

Qualquer atividade industrial requer materiais e suprimentos com os quais possa trabalhar antes que uma simples engrenagem possa começar a girar. No processo de manufatura, os materiais devem estar disponíveis e deve haver a certeza de que o suprimento será contínuo, para satisfazer as necessidades e programas de produção (HEINRITZ, 1977, p. 15).

A atividade do R.U., mesmo sendo exercida numa empresa pública está sujeita à consideração acima e Novaes e Alvarenga acrescentam:

Muito embora o conhecimento da teoria de sistemas e a aplicação de seus princípios sejam importantes no exercício profissional e no desenvolvimento científico, ainda assim, observamos que muita gente os ignora, cometendo erros imperdoáveis por desconhecê-los. No caso das empresas e órgãos do governo, por exemplo, pode-se atribuir parte da culpa pelo mau planejamento e má operação de seus serviços à excessiva departamentalização da máquina estatal. (ALVARENGA; NOVAES, 1994,p. 47).

Porém, programas governamentais de reforma administrativa não podem deixar de considerar somente o ambiente macroeconômico:

Ao considerar a atual complexidade da administração governamental brasileira e o nível de desempenho que apresenta permanecem sem resposta algumas perguntas há muito formuladas: - Por que tantas reformas no setor público? - Por que o progresso obtido pelo país nas últimas décadas não foi acompanhado pelo que se poderia chamar de "revolução administrativa" nas suas organizações públicas?(FOGUEL; SOUZA, 1985, p. 61).

Os autores exemplificam algumas das disfunções públicas:

- Descompasso entre as intenções do primeiro escalão e as medidas incrementadas pelo segundo escalão.

- Falta de compreensão da organização como sistema total.

- Grande distância entre a fonte das informações necessárias para as decisões e o local onde as decisões são tomadas (FOGUEL; SOUZA, 1985, p. 45).
Embora a obra citada seja de 1985, pode-se clarificar tais disfunções respectivamente com fatos atuais, no âmbito federal, estadual e municipal:

- Diretriz governamental em financiar o custeio de safras em determinados períodos, porém o dinheiro muitas vezes não chega no tempo certo na mão dos agricultores prejudicando o plantio.

- Falta de plano diretor na maioria das cidades brasileiras.

- Em função da diversidade cultural e econômica das regiões no Brasil, muitas decisões governamentais no âmbito administrativo não podem ser generalizadas, demandando conhecimento específico do ambiente em questão, por parte do dirigente, e regras que possam se adequar a esta realidade. Esta disfunção administrativa também pode ser verificada com frequiência em capitais e cidades maiores.

- A estas disfunções públicas, atualmente, também são acrescidos os meios compensatórios, chamados popularmente de "troca de favores", descritos mais adiante.

No âmbito legal, atualmente, mesmo depois da promulgação da Constituição Federal de 1988, dizse da necessidade de mudanças nos três poderes constituídos a saber; o Poder Legislativo, o Executivo e o Judiciário, cada qual de acordo com as atribuições que lhes são impostas legalmente, mas de forma a apresentarem complementarmente entre si, nos resultados efetivos e ágeis que a condução da administração pública brasileira exige.

Não se trata, porém, da simples importação de modelos idealizados do mundo empresarial, e sim do reconhecimento de que as novas funções do Estado em um mundo globalizado exigem novas competências, novas estratégias administrativas e novas instituições (PEREIRA; SPINK, 2001, p. 7).

Apesar de estarmos vivendo um momento de crise ética, não pode negar este fato, tendo por conceito que, a cada crise surgem oportunidades; então, no tocante a gerenciar, principalmente a máquina pública, estamos diante de uma oportunidade, no mínimo ética. Nós que administramos de uma ou outra 
forma um sistema gerencial, produtivo ou de serviços, visando à melhoria de resultados, temos sempre que estar tentando fazer de algum modo melhor aquilo que foi feito. Em outras palavras, aplicamos o princípio da pequena diferença, que em muitos casos é fator diferencial para se poder ter resultado positivo em relação a outros empreendimentos concorrentes. Com a terceirização de muitos serviços e etapas de produção, o sistema de acompanhamento em compras mostra-se de importância para apoiar e então viabilizar um negócio. Modelos de gerenciamento, como o Just-in-time, quando adotados como política empresarial e adequadamente implantados, somarão benefícios às atividades logísticas da empresa. Barroso e Gomes (1999, p. 150 ) alertam: "Isto conduz as empresas a um novo desafio, que é o de implementar sistemas de gestão do conhecimento para facilitar a eficiência, melhorar o serviço para os clientes e, ainda, aumentar a produtividade."

Os fornecedores certamente sempre estarão dispostos a participarem de um procedimento público para venda de suas mercadorias, de modo a atender aos requisitos especificados pelo comprador, dentro das normas e das condições de mercado. Daí então, ao se buscar a qualidade, tanto de fornecedores quanto de produtos, surgem técnicas que auxiliam este trabalho, tanto para fornecedores quanto para seus requisitantes.

\section{Desenvolvimento}

No desenvolvimento desta revisão bibliográfica, procurou-se primeiramente trazer elementos que compõem a referência sobre o tema estudado, acompanhamento em compras e logística, mas com informações específicas dos setores privados e públicos. Não obstante, estas formas específicas dizem respeito à administração, podendo alguns dos seus usos serem aplicados nos dois setores, desde que consideradas suas peculiaridades.

Ziliotto (1988, p. 4 ) nos informa sobre um dever dos administradores de compras quando escreve:
"[...] todas as transações de compras deveriam ser executadas dentro de normas devidamente elaboradas e baseadas em sistemas de controles internos auditáveis." Auditáveis neste contexto significa serem verificados à posteriori. Russomano (1995, p. 25 ) focaliza as funções de comprar quando escreve: "Compras, por exemplo, embora necessite de conhecimentos técnicos, exerce, de fato, uma função administrativa de identificar, negociar e acompanhar fornecedores." No sentido de nos mostrar porque acompanhar compras, num procedimento sistêmico, citamos Gurgel:

Procura-se então organizar um serviço de followup, para acompanhar o andamento dos fornecimentos e aumentar a pressão com muita antecipação, tornando-se "velha" a reclamação, por ocasião da real necessidade de material pela empresa. O reforço de uma reclamação "velha" é muito mais eficaz. (GURGEL, 1996, p. 50).

Isto pelo fato de ser mais interessante para a empresa que comprou a mercadoria, certificar-se de que a mesma será entregue, à reclamar depois pela não entrega do produto. Vemos aqui o quão imperioso para a empresa é dar andamento aos seus fluxos produtivos de uma forma ágil e não discutir com fornecedores, perdendo tempo valioso, no atraso da entrega de mercadorias adquiridas. Exemplifica o exposto:

Algumas companhias exercem pressão insistente até que os fornecedores acusem o recebimento de ordens de compra. Sabem que na maioria dos casos o fornecedor só fica legalmente obrigado a cumprir prazos e as condições do pedido, depois de ter formalmente reconhecido ou realmente atendido o pedido. Além disso, quando não se insiste na confirmação, pode, teoricamente, surgir problemas sérios se o pedido se tiver extraviado ou perdido no correio. A companhia poderá descobrir, de repente, poucos dias antes de necessitar do material para a produção, que o fornecedor não tem registro do pedido. O resultado certamente será crítico, chegando até, muito possivelmente, haver a parada de produção. (AMNER, 1979, p. 285).

Atualmente em função dos estudos existentes na área de produção das empresas e de toda a cadeia 
de fornecimento de matérias-primas, não se deseja de modo algum a quebra da sequiência de suprimento de qualquer que seja o material necessário para se produzir ou revender, mas sim a agilidade nos processos de compra e entrega. Enfatiza Gurgel (1996, p. 15 ): “A empresa, em sua dinâmica, não deve ser vista como um sistema de estoques, mas, antes de mais nada, um sistema de fluxos. A visão de estoques é uma visão estática, enquanto que a visão de fluxos é uma visão dinâmica." Dentro desta visão dinâmica de processos, surgiram técnicas específicas de gerenciamento como o Just-in-time, mas que, para ser aplicado em conjunto com outras e se ter resultado satisfatório, necessitam de pontos comuns nos objetivos e na sua execução, completando-se, como me referi na introdução deste trabalho. Esta complementação de objetivos também tem que estar voltada para uma mesma visão entre as empresas que participam daquele mercado alvo. Encontra-se também a citação do trabalho de acompanhamento em suprimentos nas observações sobre marketing reverso, em Leenders:

A função de suprimento em uma organização contribui substancialmente para os objetivos e estratégias organizacionais, quando é bem organizada e gerenciada. Como assegurar que essa função contribua com eficácia um desafio aos gerentes de abastecimento, bem como à alta administração de qualquer organização pública ou privada. (LEENDERS, 1991, p. 3).

Mas Russomano (1995, p. 68 ) diz: "Outra prática corrente é o recebimento sem inspeção também encontrado no sistema tradicional onde são aplicadas multas para a descoberta posterior de refugos. A simplificação que esta prática introduz é grande, porém exige fornecedores preparados e confiáveis."

Descreve-se o follow-up também com a palavra diligenciamento, como em Viana:

A realidade do mercado fornecedor brasileiro obriga o setor de compras a se prevenir de eventuais desvios por meio da implantação do diligenciamento, atividade que objetiva garantir o cumprimento das cláusulas contratuais, com especial atenção para o prazo de entrega acordado, acompanhando, documentando e fiscalizando as encomendas pendentes em observância aos interesses da empresa. (VIANA, 2000, p. 177).

Sendo o follow-up empregado como uma forma de se ter mais controle sobre o sistema de compras e como um maneira de se efetuar verificações periódicas e rotineiras nos suprimentos em aquisição pela organização, poderia ser chamado igualmente de monitoração em compras. Lubben analisa, à sua forma, a meta do controle do processo.

A meta do controle do processo é assegurar que o resultado da produção seja o desejado. O controle do processo, consiste em determinar a capabilidade* do processo, monitoração do seu resultado, estratificar alterações e determinar ações corretivas." *Esse termo implica que o processo tem limitações e que as técnicas de controle de processos podem ser usadas para determinar essas limitações. (LUBBEN, 1989, p. 49).

Araújo (1981, p. 97 ) também trata o assunto: “ Este serviço tem por objetivo documentar, para o acompanhamento e a fiscalização das encomendas realizadas, a observância dos prazos de entrega, previamente combinadas entre os agentes compradores, os vendedores e os produtores". [...] Este documento visa especialmente manter o Departamento de Suprimentos perfeitamente informado sobre o andamento de qualquer pedido feito aos fornecedores".

Heinritz (1977, p. 340) nomeia o acompanhamento em compras com o nome de seguimento quando escreve: "O primeiro passo no seguimento é garantir uma promessa de aceitação e de entrega da parte do vendedor." E acrescenta Heinritz (1977, p. 341): "O seguimento é seletivo. Um estudo das políticas prevalecentes mostra que menos do que um terço de todas as empresas seguem todas as encomendas colocadas para uma entrega determinada". Com relação a como proceder o follow-up, explica preliminarmente:

À medida que a necessidade de gastar se torna mais aguda, a tônica e o método do seguimento se tornam mais estritos e mais personalizados, sendo a 
seqüência usar a seguinte: carta pessoal; telegrama; telefonema e entrevista pessoal feita pelo encarregado do problema ou comprador, na fábrica do vendedor. A ação específica e o montante de pressão que são postos em ação são ajustados conforme as circunstâncias. (HEINRITZ, 1977, p. 341).

Ao falar sobre sigilo de preços, mostra uma diferença entre empresas privadas e públicas:

Deveriam as informações relativas a preços ser mantidas confidenciais? Nas compras industriais, sim. (O comprador do governo, com um sistema obrigatório de propostas seladas que devem ser abertas na presença do público, não tem esta opção. Essa é uma outra diretriz, característica de uma área particular). (HEINRITZ, 1977, p. 363).

Segundo Amner a confirmação de pedidos é descrita assim:

O follow-up de rotina pode começar assim que o recebimento do pedido for acusado. Uma cópia da ordem de compra é mantida em um arquivo separado de ordens em aberto com a confirmação não acusada, até que seja acusado o recebimento.Quando o fornecedor não a acusa, até uma semana depois de ter sido enviada a ordem, o comprador ou o expedidor telefona ou the envia um lembrete por escrito. (AMNER, 1979, p. 285).

O autor ainda assinala: "As verificações de andamento de rotina são uma garantia contra eventuais fracassos [...]." (AMNER, 1979, p. 286). Também, em relação a follow-up deparamo-nos com outra referência na área de marketing. Leenders afirma que:

No marketing reverso eficaz, não basta apenas estabelecer o contrato, assiná-lo e, então, esquecêlo. Como o verdadeiro desenvolvimento do fornecedor é um processo sempre em andamento, é imprescindível manter de modo eficiente o relacionamento. É essencial que o fornecedor conheça as dificuldades do comprador e viceversa. $O$ processo deve receber a devida atenção, o que significa acompanhamento, deliberações e lembretes adequados. (LEENDERS, 1991, p. 85).

Barroso e Gomes (1999, p. 148) dizem: "A capacidade de gerenciar, distribuir e criar conhecimento com eficiência/eficácia é fundamental para que uma organização se coloque em posição de vantagem competitiva." Essa vantagem competitiva no setor público também está relacionada atualmente em possibilitar a compra de produtos de diversas empresas dentro de um mesmo critério de seleção, como o que dispõe Telles (1995, p. 212): "Realmente, não poderia haver licitação sem que concorressem pelo menos dois interessados." Alvarenga e Novaes (1994, p. 63 ) comentam que: "No processo de suprimento, surgem problemas diversos daqueles encontrados na logística de distribuição de produtos acabados. Um problema típico é a diversificação da aquisição de matéria-prima. Muitas vezes, não é conveniente para a indústria se abastecer a partir de apenas um fornecedor, por motivos estratégicos."

Ziliotto (1988, p. 44) ressalta: "Administradores, políticos e executivos nas sociedades capitalistas igualmente como nos países socialistas, aproveitam a sua estrutura de poderes para induzir fornecedores de incluir no preço comissões e gorjetas que então são transferidos para estes administradores desonestos." Tais questões são também tratadas deste modo por Gurgel:

A função de compras nas empresas tem sido desenvolvidas dentro de um novo estado de maturidade e com técnicas cada vez mais sofisticadas. O significado desta evolução está refletido no fato de as organizações estarem começando à avaliar a performance de compras com muito mais precisão do que há muitos anos, chegando a atingir avaliações precisas e equiparáveis com trabalhos desenvolvidos em outras funções administrativas. (GURGEL, 1996, p. 37; grifo nosso).

Equipamentos computacionais existentes na Universidade Estadual de Londrina podem, de forma organizada, ajudar a conseguir melhores resultados no gerenciamento das compras na sua logística e no seu acompanhamento.

Quando se fala em avaliar o rendimento das atividades em compras, podemos citar Dias:

Um comprador eficaz deve manter um arquivo onde deve registrar a vida do produto, controlando todas 
as fases do processo de compra, as variações de preço, as modificações das quantidades solicitadas, a indicação de um nova condição de pagamento e as entradas de mercadorias correspondentes ao pedido colocado. Qualquer falha nesses registros ou insuficiência de dados pode acarretar uma má performance das atividades de Compras. Deve ser mantido atualizado devidamente a fim de ser consultado a qualquer momento. (DIAS, 1983, p. 246).

Lerner (1991, p. 87) faz a seguinte consideração: "Da mesma forma como ocorreram mudanças substanciais em todas as tecnologias (os próprios softwares e hardwares, as finanças, o marketing, os RHs e suprimentos), logicamente, agentes de aculturamento organizacional não poderiam ficar estagnados no tempo e no espaço." Ao tratarmos a administração de um empreendimento nos seus diversos aspectos, temos que estar, de uma forma holística, imbuídos da capacidade de adaptar as condições físicas do ambiente a ser administrado, às pessoas e aos métodos conhecidos e existentes empregados para administração de empresas. Um desses métodos é descrito por Albertin (2002, p. 83): "O gerenciamento da cadeia de suprimentos (Suplly Chain Management - SCM) é o gerenciamento da cadeia produtiva desde o fornecimento da matériaprima até a rede de distribuição dos produtos." Continua Albertin (2002, p. 83): "O SCM otimiza os fluxos de informação e produtos desde o recebimento do pedido, a compra de materiais, a entrega e consumo de serviços e produtos acabados." No entanto, ao se trabalhar com redes de informação, ainda explica Albertin:

Para muitas empresas, entretanto, a internet ainda não cumpriu suas promessas. Embora fazer negócio no ambiente digital possa ser original e estimulante, também pode ser frustrante, confuso e não lucrativo. Enquanto para algumas empresas o comércio online é um crescimento natural de seus negócios, para outras- particularmente dos setores de informação intensiva, tais como software, publicações e serviços financeiros - mover-se para o ambiente digital é um empenho difícil. Os problemas que essas empresas estão enfrentando têm pouco a ver com a falta de tecnologia ou informação. Elas ressentem-se de falta de regras. (ALBERTIN, 2002, p. 53).

No Ministério do Planejamento, do Brasil, existe a Secretaria de Logística e Tecnologia da Informação - SLTI. Esta secretaria “[...] é responsável pela regulamentação das compras e contratações e também pelas normas relacionadas ao uso de Tecnologia da Informação no âmbito da Administração Pública Federal". No próprio site www.planejamento.gov.br, está escrito: "O Comitê Executivo do Governo Eletrônico tem o objetivo de formular políticas, estabelecer diretrizes, coordenar e articular as ações de implantação do Governo Eletrônico, voltado para a prestação de serviços e informações ao cidadão".

Esses exemplos de métodos administrativos conduzem a um outro estágio empresarial, para algumas empresas, que é a utilização de conceitos atuais de administração no sistema de suprimentos:

[...] existe uma forma melhor de organizar e gerenciar nossos relacionamentos com os clientes, cadeia de fornecedores, desenvolvimento de produtos e operações de produção, uma abordagem na qual a Toyota foi a pioneira após a segunda guerra mundial. Chamamos essa abordagem de produção enxuta, pois trata-se de uma forma de fazer cada vez mais com cada vez menos. (WOMACK, 1998, p. Xv).

Continua Womack (1998, p. 378): “A tendência à integração dos sistemas e modularização por parte dos fornecedores é parte da criação de um sistema enxuto de fornecimento com a redução do número de fornecedores diretos na primeira camada e mudança no papel e responsabilidade dos fornecedores." A modernização evoluiu até o conceito de produção em módulos. Na mesma empresa, a produção é dividida em módulos. Cada fornecedor é responsável não somente pela entrega da matéria-prima, mas também pelo uso e aplicação do procedimento produtivo. Exemplos recentes no Brasil são a VW e a FORD. 
[...] a VW assume a inspeção final do veículo onde todos os eventuais problemas são checados e as pendências resolvidas para viabilizar a sua aprovação e liberação. Ao invés de pagar por peças entregues à linha, o pagamento é feito apenas no final da linha de montagem e após aprovação definitiva. A partir daí é que os fornecedores são pagos ("liberou, pagou"). Isso tende a gerar uma maior integração e compromisso coletivo entre todos os participantes do consórcio. (WOMACK,1998, p. 376).

No exemplo descrito acima, não foi feita nenhuma menção pelo autor em qual das fábricas instaladas pelas referidas montadoras no território brasileiro é adotado o referido modelo de gerenciamento. Criticamente, é salutar inferir que procedimentos diferentes de gestão podem estar sendo usados por um mesmo grupo empresarial para administrar fábricas distintas. Entretanto, adverte Lubben (1989, p. 167): "O processo de certificar um fornecedor, para que ele envie direto para a linha, deve ser suficientemente detalhado para assegurar que ele entregue um produto de qualidade, entre tanto, ainda existe a necessidade de monitoração interna do desempenho do fornecedor." Ainda sobre técnicas e métodos usados na administração das empresas, Rodrigues (1993, p. 32-33) comenta: "Kanban", "Just-in-time", Círculo de Qualidade, Controle estatístico do Processo são técnicas que aprimoram o uso das informações sobre o que acontece no diaa-dia de uma empresa." "[...] Tudo que envolve material deve ser de conhecimento do pessoal responsável pela gestão dos estoques.” E finaliza: "Se os compradores receberem as informações com um certo atraso, talvez não haja tempo de modificar um pedido de compra já colocado e, como resultado disso, podemos ter estoques desnecessários."

Um estágio intermediário na capacitação de parceiros comerciais pode ser verificado no uso do sistema de acompanhamento em compras, quando o fornecedor, ao diagnosticar a impossibilidade de atendimento de um pedido do comprador, entra em contato com este antes que o cliente/comprador faça uso do sistema de acompanhamento para saber se a mercadoria será ou não entregue nos prazos e condições contratados. Isto gera confiabilidade e diferenciação no atendimento aos clientes. Tal fato apresenta-se como uma inversão positiva à proposta do sistema de acompanhamento em compras.

Porém, administrar o bem público existe uma lógica fiscal que se contrapõe à lógica gerencial:

\begin{abstract}
Nesse embate, enquanto a primeira lógica praticamente só se preocupa com o quanto se gasta nos serviços públicos, atuando apenas no curto prazo, a segunda pretende tomar mais produtiva a ação da burocracia, o que implica a profissionalização dos funcionários, processo cujo retorno, sobretudo financeiro, somente ocorre no médio e longo prazos. (PEREIRA; SPINK, 2001, p. 194).
\end{abstract}

Os autores ainda acrescentam: "Esse dilema, quando não resolvido, inviabiliza a implementação integral da lógica gerencial no setor público." (PEREIRA; SPINK, 2001, p. 194)

A própria Constituição da República do Brasil, desde sua promulgação, apregoa em seu artigo no. 37, XXI, parágrafo 8: "A autonomia gerencial, orçamentária e financeira dos órgãos e entidades da administração direta e indireta poderá ser ampliada mediante contrato, a ser fixado entre seus administradores e o poder público, que tenha por objeto a fixação de metas de desempenho [...]." (BRASIL, 1988, p. 42). Bittencourt (2003), como prefeito, ressalva: "A terceirização pode acarretar vantagens ao setor público, desde que respeitados seus limites, e uma atenção profunda à legislação pátria que permite, muito embora, ainda representando um engessamento do que uma contribuição." Estas palavras, proferidas por um político exercendo mandato, revelam o conhecimento de alguns administradores públicos dos problemas que enfrentam e suas possíveis soluções porém, não raramente, esbarram na lei quando da tentativa de aplicar tal solução. Arnold (1999, p. 481) destaca: “A mensuração é necessária para todos os tipos de processo. Algumas das áreas de possíveis mensurações incluem: [...] Fornecedores. Entrega pontual, classificação, desempenho de qualidade e precisão nas cobranças." Mas, antes de mensurar o 
desempenho de um setor de compras na empresa e, mais especificamente, de um sistema de acompanhamento em compras na área de suprimentos da firma, é necessário que as pessoas envolvidas estejam treinadas para o desenvolvimento do trabalho. Desta forma, é necessário atribuir a essas pessoas responsabilidade para alguns itens que sofrerão análise de performance. Como exemplo, estão as seguintes, conforme Arnold:

Determinar as exigências de material. Desenvolver programações. Emitir ordem de compras. Emitir liberações de materiais para os fornecedores. Estabelecer prioridades de entrega. Controlar pedidos na fábrica e para os fornecedores. Cuidar de todas as atividades associadas às funções de compra e de planejamento de produção. Manter um contato íntimo com o pessoal do fornecedor. (ARNOLD, 1999, p. 225).

Se na empresa privada, tais funções podem ser minuciosamente detalhadas, em muitos casos no empreendimento público, a mesma característica de detalhe não é feita. Isto causa uma falta de diretriz na função do servidor. Este, por sua vez, na realização de suas tarefas, pode se sentir irresponsável por não fazer aquilo que não esta claramente descrito nas suas atribuições funcionais. Tal problema gera um vício conhecido como a "troca de favores" dentro das instituições públicas e até mesmo destas com a população em geral.

[...] os próprios funcionários convençam-se de que é preciso deixar de lado os resquícios do patrimonialismo, da troca de favores, das vantagens corporativas, do servilismo clientelista ao poder político, como ocorre em certas áreas da administração pública. (PEREIRA; SPINK, 2001,p. 18).

Em função da abordagem sistêmica tratada neste trabalho não se está considerando ideologias políticas ou posições político-partidárias e a citação de nomes de pessoas públicas foi feita (sem levar em consideração representações partidárias que tais pessoas possam participar) em função do interesse da pesquisa.

Finalizando esta revisão bibliográfica, cito Lerner (1991, p. 43): "Jamais considerem as adversidades como final de percurso ou esgotadas as alternativas de sobrevivência. Isso não existe no mundo da administração empresarial, pois sempre há uma melhor maneira para fazer qualquer coisa."

\section{Apresentação e tratamento dos dados}

Conforme objetivo metodológico foi feita a caracterização do sistema de acompanhamento em compras (Quadro 2 - Descrição do sistema de acompanhamento em compras-GAC). Apontou-se comparativamente na coluna de OBS. os itens que são empregados no acompanhamento em compras no R.U.. A caracterização deste sistema de acompanhamento em compras foi elaborada pelo autor deste trabalho.

Além dos itens que na comparação não são feitos como acompanhamento em compras, nota-se fundamentalmente que, no restaurante universitário, não existe uma diferenciação de classificação para os itens estocados, o que seria interessante para melhor gerenciar o acompanhamento.

$\mathrm{Na}$ caracterização do sistema de acompanhamento em compras estão relatados aspectos da logística envolvidos. Mais precisamente o que se relaciona com a recepção e movimentação física dos materiais.

A descrição do Sistema de Acompanhamento em Compras (GAC) realizada no quadro 2 é: 
Quadro 2 - Descrição do sistema de acompanhamento em compras - GAC.

\begin{tabular}{|c|c|c|}
\hline \multicolumn{2}{|c|}{ Descrição do Sistema de Acompanhamento em Compras (GAC) } & Obs: \\
\hline $\begin{array}{l}\text { - Confecção do pedido } \\
\text { para os itens A }\end{array}$ & $\begin{array}{l}\text { - Os itens de maior relevância no gerenciamento do estoque; } \\
\text { - Acompanhamento mais efetivo e rígido; } \\
\text { - O acompanhamento deve ser feito por escrito, por e-mail } \\
\text { ou fax; } \\
\text { - Fazer a confirmação da entrega pelo menos duas vezes } \\
\text { durante o prazo de entrega, desde que não seja urgente. } \\
\text { (Obs: mandar mais lembretes ao fornecedor caso o } \\
\text { comprador ache necessário.) }\end{array}$ & $\begin{array}{l}* \\
* \\
* \\
*\end{array}$ \\
\hline $\begin{array}{l}\text { - Confecção do pedido } \\
\text { para os itens B e C }\end{array}$ & $\left\{\begin{array}{l}\text { Os itens de média e menor relevância no gerenciamento do } \\
\text { estoque; } \\
\text { Acompanhamento efetivo com menor rigidez para os itens } \\
\text { C; } \\
\text { O acompanhamento pode ser feito por e-mail ou telefone } \\
\text { par os itens C; } \\
\text { - Fazer a confirmação da entrega pelo menos uma vez } \\
\text { durante o prazo de entrega para os itens B e menos } \\
\text { lembretes possíveis para o item C. Quando for de urgência, } \\
\text { não fazer lembretes. (Obs: para os itens C, fazer lembretes } \\
\text { apenas por telefone, se muito necessário.) }\end{array}\right.$ & \\
\hline $\begin{array}{l}\text { - Solicitação de } \\
\text { compra }\end{array}$ & $\begin{array}{l}\text { - } \quad \text { Caracteriza qual o tipo de produto é, se } \mathrm{A}, \mathrm{B} \text { ou C; } \\
\text { - }\left\{\begin{array}{l}\text { - uma via da solicitação de compra para o } \\
\text { fornecedor; } \\
- \text { uma via fica para o solicitante. }\end{array}\right. \\
\text { - Descrição pormenorizada do que está sendo comprado com } \\
\text { especificação de quantidades, valores e tipo de embalagem } \\
\text { e, se possível, da qualidade do produto comprado. }\end{array}$ & $*$ \\
\hline $\begin{array}{l}\text { - Acompanhamento da } \\
\text { compra (follow-up) } \\
\text { (Figura 2) }\end{array}$ & $\begin{array}{l}\text { - Para cada tipo de produto, uma ficha específica (produtos } \\
\text { A, B ou C); } \\
\text { - Pedido: número e data do pedido; } \\
\text { - Prazo de entrega: urgente - até } 3 \text { dias, normal - de } 3 \text { a } 10 \\
\text { dias, e pela data de entrega - mais de } 10 \text { dias; } \\
\text { - Ordem de compra: número, data de emissão e data } \\
\text { prevista; } \\
\text { - Data das entregas: conferência com a nota fiscal (Obs: para } \\
\text { o mesmo pedido pode ser feita mais de uma entrega.); } \\
\text { - Obs: o que for necessário acrescentar. }\end{array}$ & $*$ \\
\hline $\begin{array}{l}\text { - Recepção da compra } \\
\text { (conferência) }\end{array}$ & $\begin{array}{l}\text { - Conferir no local de entrega se as mercadorias estão de } \\
\text { acordo com o solicitado; } \\
\text { A conferência deve ser feita utilizando-se os equipamentos } \\
\text { de medição necessários, que garantam a qualidade da } \\
\text { conferência; } \\
\text { - O conferidor deve ter parâmetros para refugar toda ou } \\
\text { parte da mercadoria que está sendo entregue; } \\
\text { - Feita a recepção da mercadoria, assinar a nota fiscal de } \\
\text { acordo com o que foi conferido. }\end{array}$ & $*$ \\
\hline $\begin{array}{l}\text { - Lançamento dos itens } \\
\text { comprados no estoque }\end{array}$ & $\begin{array}{l}\text { - Após feita a conferência, dar entrada pela nota fiscal ou } \\
\text { recibo, se for o caso, das mercadorias no controle de } \\
\text { estoque; }\end{array}$ & \\
\hline
\end{tabular}


No Quadro 3 é apresentado o modelo de formulário para acompanhamento em compras. Este modelo é um exemplo criado pelo pesquisador. Nas bibliografias sobre $\mathrm{o}$ assunto poderão ser encontrados outros modelos de ficha de acompanhamento em compras.

Quadro 3 - Follow-up de compras

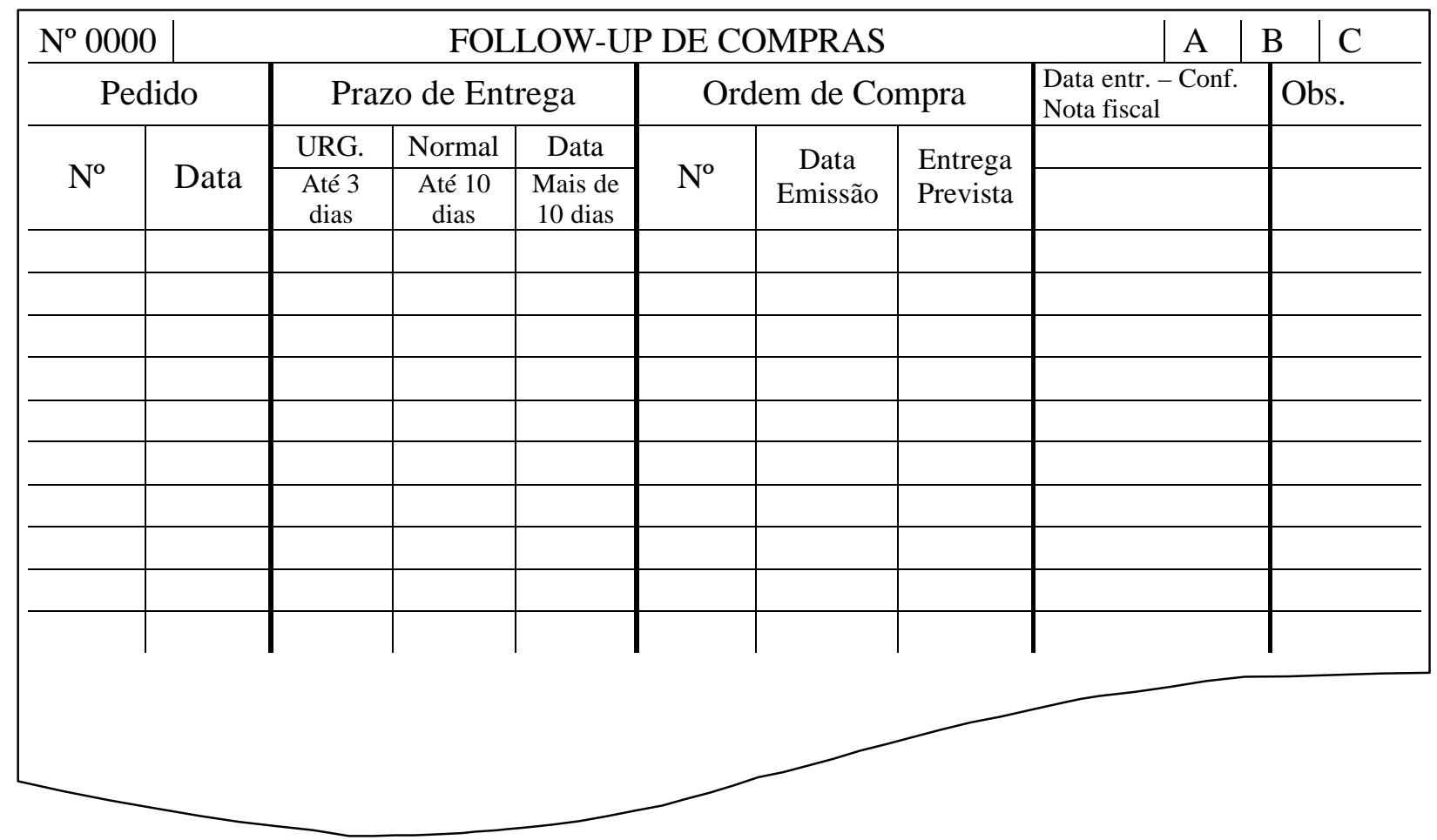

Transcrição dos dados coletados através de entrevistas

Para se fazer a gestão sobre a área de acompanhamento em compras, é necessário que a empresa possua toda a sistematização do setor compras em funcionamento, e adequadamente sincronizada. Isto quer dizer que, além de se saber detalhadamente quais são todas rotinas das tarefas existentes e os parâmetros de gestão de estoques, decididos pela cúpula da empresa, todo o pessoal do departamento de compras deve ser treinado para bem utilizá-lo. No caso da Universidade Estadual de Londrina, verificou-se que isto é feito, porém com algumas falhas, a saber:

- O acompanhamento em compras é realizado informalmente pela nutricionista do restaurante universitário, com a ajuda de seus subordinados, anotando os dados desse acompanhamento em um caderno.
- A recepção de mercadorias é deficiente:

De quatro meses para cá, quando a conferência passou a ser em todos os setores da UEL, temos constatado problemas graves. Já foram notificadas empresas que forneceram ao RU, por exemplo, 39 quilos de carne suína deteriorada, coxas e sobrecoxas de frango sem padronização e feijão carioca com 120 quilos só em impurezas. Também verificamos que uma empresa de Curitiba, que vendeu cartuchos originais HP para impressoras entregou produto falsificado [...]. (AUDITORIA..., 2003, p. 7).

- Não existe no sistema de orçamento e compras da Universidade (SICOR), anotado o resultado da conferência feita pelo solicitante da mercadoria entregue, juntamente ao arquivo ou ao cadastro do fornecedor.

- Não são verificados os cadastros anteriores dos sócios participantes de um procedimento 
licitatório. Pode acontecer, esporadicamente, a participação de uma empresa nova, mas que os sócios/titulares anteriormente participavam de empresa que praticava a sonegação de impostos. Isto faz parecer, erroneamente que a empresa participante está apta, sem restrições, a participar de uma licitação, mas verdadeiramente, ela é sucessora de uma empresa com cadastros não aprovados ou impedimentos cadastrais.

- O procedimento de acompanhamento em compras para os outros órgãos e empenhos na Universidade, com exceção do Hospital Universitário, é realizado pela Diretoria de Material no setor de pendências. Porém, só é feita uma ligação para o fornecedor um ou dois dias antes do prazo estipulado para entrega, mas não de uma forma geral, ou então, quando os solicitantes internos da UEL (professores, departamentos, centros, e outros) pedem. O comum é ligar depois do prazo de entrega ter vencido para saber porque a mercadoria não foi entregue. Neste caso, é feita uma ligação telefônica para todos os fornecedores com mercadorias pendentes de entrega.

- Outro problema relacionado aos pedidos de mercadorias que são entregues diretamente aos solicitantes, sem passar pela recepção e estocagem na Diretoria de Material, é a conferência dos mesmos. Como são terceiros que a recebem, nem sempre eles foram treinados ou instruídos sobre a forma de como proceder para fazer esta conferência. Vale lembrar que muitas vezes, estes solicitantes são professores e/ou pesquisadores.

- No período de, 26 de Fevereiro/2003 a 26 de Março/2003, foram entregues mercadorias ao R.U. sem antes ter sido feito o termo aditivo de contrato sobre a licitação no. 30/2002. Depois de ter sido feito o termo aditivo de contrato para continuação das entregas, o fornecedor emitiu as notas fiscais, do período, com data de 28 de Março de 2003.
- A apresentação dos processos de licitação também é feita pela internet acessando-se o site www.uel.br, porém não para todos os procedimentos licitatórios.

- Outro problema relativo à burocratização do sistema foi verificado na posição do órgão estudado (R.U.) dentro do organograma da Universidade. Por exemplo: quando existe um problema com algum fornecedor de mercadorias, esses problemas são relatados à diretoria de material, que se restringe a tomar as providências que a lei permite ou estipula. Também relativamente à posição do órgão no organograma da Universidade, tem-se que passar todos os problemas relativos ao gerenciamento do R.U. pelo Núcleo de Bem Estar à Comunidade (NUBEC), inclusive na formalização das compras, que formalmente é a quem o R.U. esta subordinado. Atualmente o responsável hierárquico pelo R.U. na NUBEC é uma assistente social. Cabe salientar sobre o assunto, o tempo gasto nesta tomada formal de decisões, trazendo como consequiência a falta de agilidade.

- A maneira como se procede a licitação de hortifrutigranjeiros também merece ser apontada como um problema, já que a ordem é comprar pelo menor preço do mercado. Quando o produto é comprado pela universidade, neste caso, além de ser pago o preço do dia estipulado na CEASA (Central de Abastecimento em Londrina), ainda são acrescidos os percentuais especificados na licitação, ágio ou sobrepreço. Pelo procedimento proposto é escolhido vencedor o menor percentual de acréscimo(ágio) sobre o preço de mercado entre os licitantes/fornecedores participantes. Durante o transcorrer desses contratos, acontece de os valores estipulados não serem suficientes para manutenção por parte dos fornecedores, em função do aumento ocorrido nos preços naquele período de vigência. Porque então a universidade compra sobre o preço com menor ágio e depois ainda paga termos aditivos para as mesmas mercadorias especificadas em contrato? E ainda 
os fornecedores que participaram daquela licitação não podem reclamar, pois assinaram um termo, desistindo da contestação no processo licitado pela universidade. Isto é lícito?

- Falta de critérios específicos para recepção de mercadorias e, conseqüentemente, sua conferência com o que foi especificado no momento das compras.

\section{Conclusões e recomendações}

Verificou-se no presente estudo que o sistema de acompanhamento em compras não é utilizado formalmente no órgão especificado. Mas, o seu administrador, no caso uma nutricionista, faz este serviço de acompanhamento nas compras, a serem entregues no restaurante universitário, principalmente de produtos perecíveis, de uma forma empírica e amadora. Isso demonstra a importância da utilização do sistema estudado. Também verificou-se que o resultado do acompanhamento feito no R.U. é satisfatório, pois, geralmente em função da pressão exercida para as entregas de mercadorias, elas são feitas a tempo suficiente para que, de modo geral, as refeições possam ser confeccionadas e distribuídas à comunidade universitária. O que é muito importante, e não é feito, é a anotação do resultado desse acompanhamento no cadastro do fornecedor. Quando é feito um pedido e o fornecedor envia um produto similar, no caso de hortaliças, muitas vezes a mercadoria não é devolvida, mas sim utilizada, fazendo-se as adaptações ao cardápio do dia para utilizar o que foi entregue. Isso mostra a habilidade da nutricionista em não interromper o processo produtivo das refeições naquele dia, apesar de mostrar, claramente, a falta de critérios formais em refugar um lote de mercadorias, que possam estar parcialmente impróprias ao consumo ou ao que foi convencionado no ato da compra. Formalmente, existe o setor de pendências de compras na Diretoria de Material que é o responsável pelo acompanhamento das compras efetuadas na universidade. Porém, o sistema existente para se fazer o acompanhamento resume-se, como já foi dito anteriormente, em conferir, muitas vezes sem os devidos cuidados, se as mercadorias foram entregues. Não existe uma preocupação no gerenciamento do sistema de acompanhamento em compras, de anotar e gerenciar o resultado dessas compras.

O setor de desenvolvimento de sistemas da universidade mostrou que está fazendo, sempre que necessário, mudanças que atualizem o sistema existente. No caso das compras, alguns dados exigidos no sistema, como a data de validade dos produtos, são desconsiderados por quem colhe as informações a serem mantidas no sistema.

Atualmente, em função da capacidade de armazenamento e processamento de dados dos computadores existentes, não se justifica a não anotação dos dados pertinentes ao acompanhamento em compras nos cadastros existentes, uma vez que pessoal e tempo para se realizar tal operação são disponíveis no restaurante universitário.

Quando se comparou o sistema de acompanhamento em compras existente na universidade com a caracterização do sistema exposto neste trabalho, verificou-se que, no R.U., o método de acompanhamento realizado é simples, resumindo-se ao mínimo de verificações necessárias. Um sistema administrativo de acompanhamento em compras pode, além do que foi caracterizado, conter muitas outras informações necessárias ao gerenciamento das compras na empresa. Estas informações são diferentes de empresa para empresa, demonstrando cada uma a real necessidade, de acordo com o estilo de gerenciamento do empresário. O básico necessário ao gerenciamento do acompanhamento em compras está descrito neste trabalho.

\section{Recomendações}

Primeiramente, deve-se esclarecer que algumas das recomendações aqui escritas estão relacionadas a outras áreas de conhecimento, não só de administração de empresas. Portanto, ao se analisar tais recomendações com vistas à sua implementação 
deve-se considerar o conjunto de tarefas que cada área pode realizar e o tempo condizente para tal implementação, para se ter sucesso na realização de tais procedimentos e não se incorrer em erros, ao se modificar algo existente.

Recomenda-se que:

- Imediatamente todos os resultados da recepção de mercadorias e o acompanhamento nas compras sejam anotados em cadastros dos fornecedores, existentes no sistema de compras da Universidade;

- Ao se analisar o cadastro de proponentes à uma licitação pública, verifique-se se os sócios da empresa participante não fizeram parte de empresa sucessora com cadastros bloqueados, em função de inadimplência com impostos e outros tributos.

- Indique-se aos legisladores, a formulação de leis que contemplem e aperfeiçoem o problema de compras, visando à minimização da burocracia existente e obtenção de resultados menos onerosos aos cofres públicos, na administração pública brasileira, com a colaboração dos dados específicos desta pesquisa para o problema em questão;

- Que a Universidade Estadual de Londrina estude a possibilidade de adoção do sistema de concessão pública para o R.U., assim como são as cantinas no campus universitário e outros serviços públicos explorados no município de Londrina e no Estado do Paraná;

- Que se façam outros estudos sobre o tema e áreas aqui abordados, como por exemplo, a análise da eficiência do sistema público de administração em compras, onde poderiam estar sendo verificados possíveis vícios nas compras públicas. Ex. Licitação dirigida a um fornecedor que combina com a empresa pública o preço vencedor e, durante o transcorrer do tempo, fornece mais do que foi licitado, através de termos aditivos de contrato; ou então, poucos fornecedores cadastrados que se revezam "controladamente" nos processos de licitação ou colocação de propostas por empresas existentes apenas burocraticamente, mas que, de fato, não podem fornecer, as mercadorias licitadas por só existirem no papel (empresas fictícias), entre outros; verificação de resultados e custos de produção em refeições no R.U.; aspectos trabalhistas envolvidos na administração do R.U.; benefícios advindos da administração, pela Universidade, do R.U. (Em Londrina e outras localidades); estudos jurídicos, enfocando causas e conseqüências sobre o assunto aqui pesquisado, entre outros;

- Que se institua imediatamente parâmetros de conferência específicos das mercadorias compradas, nos procedimentos licitados na Universidade Estadual de Londrina.

\section{Referências}

ALBERTIN, Alberto Luiz. Comércio eletrônico. 4. ed. São Paulo: Atlas, 2002.

ALVARENGA, Antonio Carlos; NOVAES, Antonio Galvão N. Logística aplicada: suprimento e distribuição física. 2. ed. São Paulo: Pioneira, 1994.

AMNER, Dean S. Administração de material. Rio de Janeiro: LTC. 1979.

ARAÚJO, Jorge Sequeira de. Administração de materiais. São Paulo: Atlas, 1981.

ARNOLD, J. R. Tony. Administração de materiais: uma introdução. São Paulo: Atlas, 1999.

AUDITORIA pede mais rigor no recebimento de materiais. NOTÍCIA, Londrina, 22 jan. 2003. p. 7.

BARROSO, Antonio Carlos de Oliveira; GOMES, Elizabeth Brás Pereira. Tentando entender a gestão do conhecimento. Rio de Janeiro: RAP, 1999.

BRASIL. Constituição (1988). Texto Constitucional de 5 de Outubro de $1988 \mathrm{com}$ as alterações adotadas pelas Emendas Constitucionais no. 1/92 a 22/99 e Emendas Constitucionais de Revisão no. 1 a 6/94. Brasília, DF: Ed. Atual, 1999.

BRASIL. Ministério do Planejamento. Secretaria de Logística e Tecnologia da Informação - SLTI. Brasília, DF. Disponível em: 〈http://www.planejamento.org.br $>$. Acesso em: 26 maio 2003. 


\section{O sistema de acompanhamento em compras e logística numa organização pública}

BITTENCOURT, Júlio. A terceirização de serviços no setor público. Folha de Londrina, Londrina, 23 abr. 2003. Caderno 1, p. 2.

CONTANDRIOPOULOS, André Pierre et al. Saber preparar uma pesquisa. São Paulo: Hucitec: Abrasco, 1994.

DIAS, Marco Aurélio P. Administração de materiais. Uma abordagem logística. São Paulo: Atlas, 1983.

DIAS, Marco Aurélio P. Administração de materiais. São Paulo: Atlas, 1985. Edição Compacta.

DI PIETRO, Maria Sylvia Zanella. Direito administrativo. São Paulo: Atlas, 1996.

FOGUEL, Sergio; SOUZA, Carlos César. Desenvolvimento e deterioração organizacional. São Paulo: Atlas, 1986.

GIACOMONI, James. Orçamento Público. 8. ed. São Paulo: Atlas, 1998.

GOLDRATT, Eliyahu M.; COX, Jeff. A Meta. São Paulo: Educator Editora, 1993.

GURGEL, Floriano do Amaral. Administração dos fluxos de materiais e de produtos. São Paulo: Atlas, 1996.

HEINRITZ, Stuart F. Compras: princípios e aplicações. São Paulo: Atlas, 1977.

LAKATOS, Eva Maria; MARCONI, Marina de Andrade. Metodologia científica. 2. ed. São Paulo. Atlas, 1991.

LEENDERS, Michiel R. Marketing Reverso: um novo conceito no relacionamento comprador-vendedor. São Paulo: Makron, McGraw-Hill, 1991.

LERNER, Walter. Organização Participativa: como a empresa brasileira pode enfrentar esse desafio. São Paulo: Nobel, 1991.
LUBBEN, Richard T. Just-In-Time - Uma estratégia avançada de produção. 2. ed. São Paulo: McGraw-Hill, 1989.

MIRANDA, Mac-Dowell dos Passos. Manual de organização. São Paulo: Atlas, 1968.

OISHI, Michitoshi. TIPS - Técnicas integradas naProdução e Serviços. São Paulo: Pioneira, 1995.

OLIVEIRA, Marcos Antonio de. ISO 9000: Guia de Implantação. São Paulo: Atlas, 1995.

PEREIRA, Luiz Carlos Bresser; SPINK, Peter. Reforma do Estado e Administração Pública Gerencial. 4. ed. Rio de Janeiro: Fundação Getúlio Vargas, 2001.

REIS, Heraldo da Costa. Contabilidade municipal - teoria e prática. Rio de Janeiro: LTC, 1979.

RODRIGUES, Gerson José Jorio. Redução de Estoques em 3 Dimensões. São Paulo: IMAM, 1993.

RUSSOMANO, Vitor Henrique. Planejamento e Controle da Produção. 5. ed. São Paulo: Pioneira, 1995.

TEIXEIRA, Aníbal. Reengenharia no Governo. São Paulo: Makron Books, 1996.

TELLES, Antonio A. Queiroz. Introdução ao Direito Administrativo. São Paulo: Ed. Revista dos Tribunais, 1995.

VASCONCELOS FILHO, Paulo de. Planejamento estratégico para a retomada do desenvolvimento. Rio de Janeiro: LTC, 1985.

VIANA, João José. Administração de Materiais - Um enfoque prático. São Paulo: Atlas, 2000.

WOMACK, James P. A mentalidade enxuta nas empresas: elimine o desperdício e crie riquezas. Rio de Janeiro: Campus, 1998.

ZILIOTTO, Newton. Curso de Sistematização em Compras. Curitiba: CEAG-PR, 1988. 